\title{
Obesity Trends in School Children of Madinah Al Munawarrah-A Cross-Sectional Study
}

\author{
Atta ur Rehman Khan* and Meshal Al Malki \\ Clinical Nutrition Department,Prince Muhammad Bin Abdulaziz Hospital, Madinah
}

King Abdullah International Medical Research Center, KAIMRC

King Saud Bin Abdulaziz Unversity for Health Sceinces, KSAU-HS

Ministry of National Guard Health Affairs, Saudi Arabia

*Corresponding author: Atta ur Rehman Khan, Clinical Nutrition Department, Saudi Arabia, Email: RehmanAu@NGHA.MED.SA

ARTICLE INFO

Received: 蔧 August 24, 2019

Published: 慧 September 04, 2019

Citation: Atta ur Rehman Khan, Meshal Al Malki. Obesity Trends in School Children of Madinah Al Munawarrah-A Cross-Sectional Study. Biomed J Sci \& Tech Res 21(1)-2019. BJSTR. MS.ID.003538.

\section{ABSTRACT}

Background: Obesity is one of the three gravest threats to human health, but no study has been conducted in the $2^{\text {nd }}$ holiest city of Muslims Al Madinah Al Munawarrah located on western part of Saudi Arabia.

Objectives: This study aimed to evaluate the prevalence of overweight and obesity in school children.

Methods: Participants were healthy schoolboys and girls aged $05-18$ years. It was a cross-sectional stratified study. Total sample size was 6000 consisting of 3000 boys and 3000 girls Twenty (20) schools were selected with random stratification with the help of Ministry of education. Data were collected between April - December 2017. Height and weight of children were measured to calculate percentiles for BMI-for-age and -sex according to the 2000 Centers for Disease Control and Prevention (CDC) growth charts, Overweight and obesity was defined as BMI-for-age/sex $\geq \_85$ th and $\geq 95$ th percentile respectively.

Results: The overall prevalence of obesity was $14.7 \%(n=588)$. Obesity Prevalence in boys was $16 \%(n=347)$ and in girls was $14 \%(n=241)$. The overall prevalence of overweight was $15.4 \%(n=616)$. The Prevalence in boys was $16 \%(n=366)$ and in girls was $14 \%(n=250)$.

Conclusions: Overweight and obesity in school children in $\mathrm{Al}$ Madinah $\mathrm{Al}$ Munawawarh is as high as global prevalence is. Intervention and prevention programs should focus on primary school students. Ministry of education and Ministry of health have a key role. Dietitians and public health Workers can play an effective to control obesity.

\section{Introduction}

Obesity is one of the three gravest threats to human health and survival beside undernutrition and climate change [1]. One of the major consensus achieved by health researchers and medical experts at the beginning of the 21st century is all about obesity as a medical condition, a chronic and relapsing disease [2]. Obesity now is one of the largest contributors of poor health in the world. There has been an unabated rise in obesity prevalence in all countries in the past four decades, and no country has succeeded in reversing its obesity epidemic [3]. Despite large allocation of resources to prevent and treat obesity, it continues to rise across the continents, borders, races and ages consistently. The recent prevalence is higher than ever in history [4]. The recent reports confirm the fastest rise in children with obesity by tenfold over the past four decades [5]. In 2014, around 41 million children under 5 years of age were reported with overweight or obesity world over [6]. The risk for adulthood non-communicable diseases is increased by childhood obesity. These so called non-communicable diseases in adults are reported to cause $71 \%$ of the world's deaths [7].

In Saudi Arabia, previous reports on the prevalence of overweight and obesity were limited to a single city male school 
child such as prevalence of obesity was $22 \%$ in Riyadh, $15 \%$ in Jeddah, $23 \%$ in eastern province, 17\% in Al Khobar [8-10]. At the national level, only one representative study has been done in Saudi Arabia to date with a large sample size of 19317 healthy children and adolescents from 5 to 18 years of age. The prevalence of overweight, obesity and severe obesity in all age groups was $23.1 \%, 9.3 \%$ and $2 \%$, respectively, with boys having a significantly higher prevalence of obesity $(10.1 \%$ vs $8.4 \%$; $\mathrm{P}<.001)$ and severe obesity $(2.3 \%$ vs $1.6 \%$; $\mathrm{P}<.001)$ than girls. The study showed that the girls had a significantly higher prevalence of overweight $(23.8 \%$ vs $22.4 \%$; $\mathrm{P}=.014$ ). The 2005 Saudi reference data set was used to determine the prevalence of obesity with the criteria set in 2007 WHO reference [11]. The recent obesity epidemic is not entirely due to major changes in society. There is a very strong genetic predisposition to obesity as contrary to the commonly discussed lifestyle changes.

When studied, the identical twins are very similar in weight. If they have obesity, they generally both have obesity, and if they are thin, they are generally both thin [12]. It is now confirmed that genetic influences have an important role in determining human fatness in adults, whereas the family environment alone has no apparent effect [13]. Therefore, epigenetic mechanisms may explain recent increases in obesity [14]. Many more review, rodents and human studies have highlighted and explained the epigenetics mechanism behind the increased prevalence of obesity in the past 4-5 decades [15-21]. Obesity emerges from a lethal combination of exposure of the child to an obesogenic environment (unhealthy environment) [22] and inadequate behavioral and biological responses to that environment. There are number of health complications having both physical and psychological dimensions through childhood, adolescence and into adulthood. Obesity itself is a direct cause of morbidities in childhood including gastrointestinal, musculoskeletal and orthopedic complications, sleep apnea, and the accelerated onset of cardiovascular disease and type-2 diabetes, as well as the comorbidities of the latter two non communicable diseases [23]. At the same time, obesity in childhood can cause behavioral and emotional difficulties, such as depression, and can also lead to stigmatization and poor socialization and reduce educational attainment. [24-25]. Childhood obesity is a strong predictor of adult obesity, which has well known health and economic consequences, both for the individual and society as a whole [26-27]. Recently, longitudinal studies suggest that reduction in BMI in adulthood can reduce the risk of morbidity and mortality [28].

Despite the prevalence of the obesity at a faster pace in the kingdom, one hardly finds any regular National Nutrition survey such as National Health and Nutrition Examination survey (NHANES) in USA. As a result, there is also missing pediatric health and Nutrition data base that can be used to formulate policy on how to curb the Obesity and associated comorbidities in the kingdom. However, single city reports showing frequently that the children in Saudi Arabia are suffering from the menace of Obesity. The studies conducted in the kingdom, consistently reveal the upward trends in obesity in both genders. Many small nutrition surveys and studies have been done in eastern, central and southern region but no study was carried out in western region and the Holy city of Al Madinah Al Munawarrah till to date. Therefore, based on various reports and keeping in view the sedentary lifestyle, unhealthy dietary habits and compromised health status of children, this study aimed to investigate prevalence of obesity and overweight in school going children in the $2^{\text {nd }}$ Muslim holiest city of Madinah Al Munawarrah. We now report our study methods and results.

\section{Methods}

\section{Study Design}

It was a Cross-sectional Study. A pre structured self-administered questionnaire was used to collect the data on demographics, anthropometrics, dietary and physical lifestyle of the children. An informed consent was filled either by parent or guardian or school administration. Dietary intake was recorded by Food Frequency Questionnaire (FFQ) which will be published elsewhere.

\section{Setting}

Government schools in Madinah Research staff from Prince Muhammad Bin Abdulaziz Hospital -National Guard Health Affairs, Clinical Nutrition department carried out data collection, entry and analysis in the 2nd Holy Most city in the Muslim world Al Madinah Al Munawarrah west of Kingdom of Saudi Arabia. Ministry of Education in Madinah Al Munawarrah collaborated in completion of the project. The data collection was done between April December 2017.

a) Ethical Approval The study was approved by Institutional review Board of King Abdullah International Medical Research Centre and King Saud Bin Abdulaziz university, Ministry of National Guard Health Affairs.

\section{Sampling technique, inclusion and Exclusion criteria:}

Sampling was done by random selection of schools and classes. Whereby all city schools in Madinah were stratified based on areas into four strata based on directions (east, west, north and south). An estimated population of the school children in Madinah is in the range of 50-60 thousand in all 100 plus schools. Probability stratified sampling was done to reach to a size of 6000 students with confidence Interval of $95 \%$. Approximately $50 \%$ boys and $50 \%$ girls. This was around $10-15 \%$ of the total students in Madinah city. Inclusion Criteria was the healthy schoolboys and girls aged 05-18 years whereas any student with diagnosed medical problem such as Diabetes Mellitus Type I was excluded. Sampling was done with random stratification of schools and then randomly selection of classes in stratified schools. Total sample size was 6000 , which further divided into 3000 boys and 3000 girls (10\% of overall population of school students). Twenty (20) schools were selected randomly out of total 110 schools with the help of Ministry of education. 


\section{Outcome Measures}

Primary measures were Body Mass Index and which was calculated as $\mathrm{Kg} / \mathrm{m}^{2}$, which was also used as a measure of obesity because it correlates well with adiposity [29]. Anthropological measures of weight and height were taken following the interview. All subjects were measured when they were barefoot and wear only light clothes. Weight was measured by standardized calibrated scales to the nearest $0.1 \mathrm{~kg}$ and height was taken to the nearest $0.1 \mathrm{~cm}$ using the standardized wall-mounted height boards with a sliding head piece. Children's height and weight were used to calculate percentiles for BMI-for-age and-sex according to the 2000 Centers for Disease Control and Prevention (CDC) growth charts, Overweight/ obesity was defined as BMI-for-age $>85$ th percentile of the 2000 sex-specific CDC growth charts; obesity was defined as $>95$ th percentile [30].

\section{Statistical Analysis}

Data was coded and analyzed using JMP SAS Statistical Package. Descriptive statistics was used to determine mean and standard deviations for Age, Weight, Height and Body Mass Index of all sample and sub-groups based on age categories. Frequencies were calculated for students who were overweight and obese. All the analysis was done as first combined and then separately for male and female students.

\section{Results}

A total number of 3987 school children responded on selfadministered questionnaire which was initially distributed to 6000 children. 3000 were girls and 3000 were boys. The response rate was recorded as 67\%. Out of total 3987 children, 2222 (56\%) were boys and 1765 (44\%) were girls who responded with fully or partially filled questionnaire. All above means and standard deviations are in the (Table 1). The demographics showed that the overall mean age for the whole sample was 14 years (SD \pm 2.54 ). Mean age for boys was 14.4 years $(\mathrm{SD} \pm 2.27$ ) and girls was 13.88 years $(\mathrm{SD} \pm 2.81$ ). The overall mean age (both boys and girls included) in Category- I (5-8 years) was 7.71( $\mathrm{SD} \pm 0.63$ ), category-II (9-13 years) was 11.82 (SD \pm 1.31 ) and Category-III (14-18 years) was 15.68 (SD \pm 1.35 ). The overall mean weight was 50.3 (SD \pm 17.6$)$.

Mean weight for boys was 52.53 (SD \pm 18.26 ) $\mathrm{kg}$. Mean weight for girls was 47.54 (SD \pm 16.48 ) $\mathrm{kg}$. In boys the mean weight in Category- I (5-8 years) was 26.05 (SD \pm 6.08 ), category-II (9-13 years) was 40.7 ( $\mathrm{SD} \pm 13.2$ ) and Category-III (14-18 years) was 57.9 ( $\mathrm{SD} \pm 17.45$ ).In girls the mean weight in Category- I (5-8 years) was 22.9 (SD \pm 5.7), category-II (9-13 years) was 42.08 (SD \pm 14.08 ) and Category-III (14-18 years) was 53.46 (SD \pm 14.99 ). The overall height was 1.54 ( $\mathrm{SD} \pm 0.12$ ) meters. Mean height for boys was 1.57 $(\mathrm{SD} \pm 0.13$ ) meters. Mean height for girls was $1.50(\mathrm{SD} \pm 0.11$ ) meters. For boys the mean height in Category- I (5-8 years) was 1.26 (SD \pm 0.04 ), category-II (9-13 years) was 1.45 (SD \pm 0.09 ) and Category-III (14-18 years) was 1.63 (SD \pm 0.09 ). For girls the mean height in Category- I (5-8 years) was 1.23 (SD \pm 0.06 ), category-II (9-13 years) was $1.46(\mathrm{SD} \pm 0.10)$ and Category-III (14-18 years) was 1.55 ( $\mathrm{SD} \pm 0.06$ ) (Table 1). Body Mass Index (2000 Centre for Disease Control -CDC reference) [30]. The overall mean Body Mass Index (BMI) was $20.7(\mathrm{SD} \pm 5.84) \mathrm{KG} / \mathrm{M}^{2}$. Mean Body Mass Index (BMI) for boys was 20.78 (SD \pm 6.03 ) KG/ $\mathrm{M}^{2}$ and mean Body Mass Index (BMI) for girls was $20.64(\mathrm{SD} \pm 5.5) \mathrm{KG} / \mathrm{M}^{2}$.In boys the mean BMI in Category- I (5-8 years) was 16.08 (SD \pm 2.75 ), category-II (9-13 years) was $18.95(\mathrm{SD} \pm 4.56)$ and Category-III (14-18 years) was 21.62 (SD \pm 6.38). For girls the mean BMI in Category- I (5-8 years) was 14.94 (SD \pm 2.59 ), category-II (9-13 years) was 19.25 ( $\mathrm{SD} \pm 4.86$ ) and Category-III (14-18 years) was 22.10 (SD \pm 5.65$)$.All above means and standard deviations are in the (Table 1a).

Table 1: Overall School Children Demographics in the Holy city of Madinah Al Munawarah.

\begin{tabular}{|c|c|c|c|c|c|c|}
\hline \multirow{2}{*}{ Variables } & \multicolumn{4}{|c|}{ Overall } \\
\cline { 2 - 7 } & \multicolumn{2}{|c|}{ Girls (n= 1765) } & \multicolumn{2}{c|}{ Boys (n= 222) } & \multicolumn{2}{c|}{ Both sexes (n= 3987) } \\
\cline { 2 - 7 } & Mean & SD & Mean & SD & 13.88 & Mean \\
\hline Age (years) & 14 & 2.54 & 14.4 & 18.26 & 47.54 & 16.48 \\
\hline Weight(kg) & 50.3 & 17.6 & 52.53 & 0.13 & 1.50 & 0.11 \\
\hline Height(M) & 1.54 & 0.12 & 1.57 & 6.03 & 20.64 & 5.5 \\
\hline Body mass index (BMI) & 20.7 & 5.84 & 20.78 & \multicolumn{2}{c|}{. } \\
\hline
\end{tabular}

Table 1(a): Age categories and School Children Demographics in the Holy city of Madinah Al Munawarah.

\begin{tabular}{|c|c|c|c|c|c|c|c|c|c|c|c|c|}
\hline \multirow{3}{*}{ Variable } & \multicolumn{4}{|c|}{5 - 8 years } & \multicolumn{4}{|c|}{$9-13$ years } & \multicolumn{4}{|c|}{14 - 18 years } \\
\hline & \multicolumn{2}{|c|}{ Boys $(n=32)$} & \multicolumn{2}{|c|}{ Girls $(n=110)$} & \multicolumn{2}{|c|}{ Boys $(n=636)$} & \multicolumn{2}{|c|}{ Girls $(n=624)$} & \multicolumn{2}{|c|}{ Boys $(n=1554)$} & \multicolumn{2}{|c|}{ Girls $(n=1031)$} \\
\hline & Mean & SD & Mean & SD & Mean & SD & Mean & SD & Mean & SD & Mean & SD \\
\hline Age (Years) & 8.06 & 0.80 & 7.60 & 0.54 & 11.82 & 1.29 & 11.83 & 1.33 & 15.60 & 1.31 & 15.80 & 1.40 \\
\hline Weight(kg) & 26.05 & 6.08 & 22.9 & 5.7 & 40.7 & 13.2 & 42.08 & 14.08 & 57.9 & 17.45 & 53.46 & 14.99 \\
\hline Height(M) & 1.26 & 0.04 & 1.23 & 0.06 & 1.45 & 0.09 & 1.46 & 0.10 & 1.63 & 0.09 & 1.55 & 0.06 \\
\hline $\begin{array}{l}\text { Body Mass } \\
\text { Index (BMI) }\end{array}$ & 16.08 & 2.75 & 14.94 & 2.59 & 18.95 & 4.56 & 19.25 & 4.86 & 21.62 & 6.38 & 22.10 & 5.65 \\
\hline
\end{tabular}




\section{a) Prevalence of Obesity (BMI $>95^{\text {th }}$ Percentile)}

In this study the overall prevalence of obesity was $14.7 \%(\mathrm{n}=$ 588). Boys with obesity were $16 \%(n=347)$ and in girls was $14 \%$ $(n=241)$. In boys the obesity prevalence in Category- I (5-8 years)

Table 2: Trends in school children with overweight and Obesity in the Holy city Al Madinah Al Munawarrah.

\begin{tabular}{|c|c|c|c|c|c|c|c|c|c|c|c|c|c|c|c|c|c|c|}
\hline \multirow{3}{*}{ Variable } & \multicolumn{6}{|c|}{ Overall } & \multicolumn{4}{|c|}{5 - 8 years } & \multicolumn{4}{|c|}{$9-13$ years } & \multicolumn{4}{|c|}{14 - 18 years } \\
\hline & \multicolumn{2}{|c|}{ Both } & \multicolumn{2}{|c|}{ Boys } & \multicolumn{2}{|c|}{ Girls } & \multicolumn{2}{|c|}{ Boys } & \multicolumn{2}{|c|}{ Girls } & \multicolumn{2}{|c|}{ Boys } & \multicolumn{2}{|c|}{ Girls } & \multicolumn{2}{|c|}{ Boys } & \multicolumn{2}{|c|}{ Girls } \\
\hline & $\mathbf{N}$ & $\%$ & $\mathbf{N}$ & $\%$ & $\mathbf{N}$ & $\%$ & $\mathbf{N}$ & $\%$ & $\mathbf{N}$ & $\%$ & $\mathbf{N}$ & $\%$ & $\mathbf{N}$ & $\%$ & $\mathbf{N}$ & $\%$ & $\mathbf{N}$ & $\%$ \\
\hline Obesity & 14 & 241 & 16 & 347 & 14.7 & 588 & 6 & 7 & 9 & 3 & 14 & 85 & 14 & 86 & 14 & 149 & 17 & 258 \\
\hline $\begin{array}{l}\neg \text { Over } \\
\text { weight }\end{array}$ & 14 & 250 & 16 & 366 & 15.4 & 616 & 9 & 10 & 13 & 4 & 14 & 88 & 18 & 117 & 15 & 152 & 16 & 245 \\
\hline
\end{tabular}

\section{b) Prevalence of Overweight (BMI $>85^{\text {th }}$ Percentiles)}

The overall trends in overweight was also similar to obesity as $15.4 \%(n=616)$. The boys with obesity were $16 \%(n=366)$ and the girls with obesity were $14 \%(n=250)$.Overweight trends in boys in Category- I (5-8 years) was $13 \%(n=4)$, category-II (9-13 years) was $18 \%(n=117)$ and Category-III (14-18 years) was $16 \%$ $(n=245)$.Overweight trends in girls in Category- I (5-8 years) was $9 \%(\mathrm{n}=10)$, category-II (9-13 years) was $14 \%(\mathrm{n}=88)$ and CategoryIII (14-18 years) was $15 \%(n=152)$ (Table 2).

\section{Discussion}

Obesity and overweight know no borders and cuts across all age groups, genders, ethnic and all social-economic classes. Therefore, we are now a faced with a bigger problem as globosity because of global epidemic occurring in both developed and developing countries [31]. confirmed in 1997 by World Health Organization as a worldwide phenomenon [32]. A higher body weight is associated with an increased incidence of a number of medical conditions, including type 2 diabetes mellitus, insulin resistance, cardiovascular disease, stroke, some types of cancer, and nonalcoholic fatty liver disease [33]. Obesity in childhood and adolescence represents a serious health problem because it tends to continue into adulthood [34]. The present study is the first of its kind in the school children of Madinah at all levels of schooling such as primary, elementary and secondary. In this study the overall prevalence of obesity in school children was $14.7 \%$. The obesity Prevalence in boys was higher than girls $16 \%$ vs $14 \%$. In boys the highest prevalence was recorded Category-III (14-18 years) as $17 \%$.Prevalence was decreased as we move down to the lesser age students ( $14 \%$ in $9-13$ years and $9 \%$ in 5 -8 years).At the same time the highest prevalence of obesity in girls was same as $14 \%$ in both age groups of 9-13 and 14-18 years. The similar pattern exists for the prevalence of overweight in boys and girls as observed in present study (16\% vs 14\%). This pattern of increase in overweight prevalence is similar to obesity prevalence in our study as both increase with the age in both boys and girls' students. This is similar to the both International and national childhood trends [35].

International comparisons can be made with our research findings. Our findings on obesity trends in Madinah school children was $9 \%(n=3)$, category-II (9-13 years) was $14 \%(n=86)$ and Category-III (14-18 years) was $17 \%(n=258)$.For girls the obesity prevalence in Category- I (5-8 years) was 6\% (n=7), category-II (913 years) was $14 \%(n=85)$ and Category-III (14-18 years) was also $14 \%(n=149)$ (Table 2).

are similar to the global trends recorded in the findings of WHO reports as global trends show the prevalence of childhood (aged 5-19 y) overweight and obesity has increased rapidly from as low as $4 \%$ in 1975 to $18 \%$ in 2016 . This increase has been reported equally among both boys and girls: in 2016 18\% of girls and 19\% of boys were overweight. While just under $1 \%$ of children and adolescents aged 5-19 were obese in 1975, more 124 million children and adolescents ( $6 \%$ of girls and $8 \%$ of boys) were obese in 2016. 35. The prevalence of childhood obesity in Kingdom of Saudi Arabia (KSA) is $17.4 \%$ reported by WHO in 2016.In 1975 the prevalence was just $1 \%$, in 2000 it rose to $9.8 \%$ and 2010 to 14.3.The prevalence of childhood (5-19 y) obesity in other Gulf countries like Kuwait on top with 22.9\%, Qatar 19.5\%, Egypt 17.6\%, Bahrain 17.2\%, UAE 17.3\%.Globally Cook island $32.2 \%$ ,Niue 29\%, Marshal island 26.6 and USA 21.4\%. 35 Locally, Saudi Arabian childhood obesity data is scarce during this decade. Local data searches yield no encouraging results. Internationally through major search engines PubMed, google scholar, Cochrane we hardly found 2-3 national data sets in studies. These data sets however are old enough to be questioned for its applicability now in 2019. It is now beyond doubt that obesity and overweight is fast rising in Madinah as in the other region of the kingdom. As reported earlier [36] in the only national study on prevalence of childhood obesity in Saudi Arabia. The prevalence of overweight, obesity and severe obesity in all age groups was $23.1 \%, 9.3 \%$ and $2 \%$, respectively, with boys having a significantly higher prevalence of obesity $(10.1 \%$ vs $8.4 \%$; $\mathrm{P}<.001)$ and severe obesity $(2.3 \%$ vs $1.6 \%$; $\mathrm{P}<.001)$ than girls. However, girls had a significantly higher prevalence of overweight (23.8\% vs 22.4\%; $\mathrm{P}=.014$ ).11 The prevalence of overweight, obesity, and severe obesity in adolescents from 13 to 18 years of age was $26.6 \%, 10.6 \%$ and $2.4 \%$, respectively. In the same it was reported that a significantly lower prevalence of overweight $23.9 \%$ vs 20.4\%; $\mathrm{P}<.001$ ) and obesity (9.5\% vs 5.7\%; $\mathrm{P}<.001$ ) when the CDC reference was used. The same pattern prevails here in Madinah as we found around $15 \%$ prevalence of obesity and a little above $15 \%$ overweight in school children. Total combine percentage of overweight and obese exceeds $30 \%$, which is quite alarming. In Saudi Arabia. The CDC reference underestimates the prevalence of overweight and obesity [11]. 
These results show that the combined obesity and overweight $(32 \%)$ in Madinah ranks $3^{\text {rd }}$ highest in the kingdom as per current available published results in many other studies $[37,38]$. The Eastern province being $1^{\text {st }}$ in the ranking list with $42 \%$ prevalence and Al Riyadh being $2^{\text {nd }}$ in the list with combined prevalence of Overweight and obesity of $37.5 \%$ and now Madinah 3rd with a prevalence of $32 \%$. This can be placed as every 1 out of 3 teenagers in this city is overweight or obese. This should ring an alarm bell for the Ministry of health and other policy makers responsible for the children health in Madinah.

\section{Study Strengths}

As far as strengths are concerned, this is the first time we have laid the foundation of scientific health data base of children with present results on health status of our children in the $2^{\text {nd }}$ holiest city of Muslims after Makkah in the whole world. The best timing to take action is now if we want to win a fight against obesity in this holy city. The implications are clearly evident for the Ministry of Education as well. This will be a baseline data for future researches to start with other health objectives in children of this holy city. This can also act a health quality improvement benchmark as well as a first ever available reference standard. These results can be instrumental to gauge the future changes in prevalence of obesity and overweight at local level. Thus, can be used as a yardstick to foresee the projections of the non-communicable diseases in Madinah in next 5-10 years.

\section{Study Limitations}

We have got few limitations to share in our study. First, the response rate of completion of questionnaire with food frequencies and anthropometrics was 66\%. This is slightly higher than expected. The $34 \%$ non-responsiveness in our study data might create a sample bias and ultimately in prevalence results in both directions. Secondly, we used the CDC 2000 reference standard for BMI which underestimates the prevalence when compared with WHO standards 2007. This might make it difficult to compare with studies done by using IOTF or WHO cut offs. As future ideas, it can be suggested, Saudi Arabia needs to establish a national governmental database on overweight and obesity for children through 10 years National Health and Nutrition Examination survey such as conducted in the US. Future research also needs to study home environment as well as look at how nutrition and physical activity is promoted in the school environment in Saudi Arabia. How good are schools in demonstrating best practices to curb the menace of obesity? How can one apply these best practices to schools at national level? These are important potential research questions to be answered in the near future.

\section{Conclusion}

We can conclude from our study that obesity in children is at alarming levels in Madinah and thus the risk of non-communicable diseases is likely to rise in this city in near future at a drastic pace. This state of health of school children of Madinah likely to incur huge cost for treatment of obesity related diseases. Concerted efforts are required at war footings jointly by Ministry of Health ( $\mathrm{MOH})$, Ministry of Education (MOE) in collaboration with other relevant governmental agencies and Nutrition healthcare professional bodies in order to tackle the obesogenic environment in the Holy city of Madinah Al Munawarrah. This is the high time to adopt A whole- of-Government and whole-of-society approach to tackle the obesogenic environment otherwise no other approach will be able to halt obesity.

\section{Acknowledgement}

We greatly acknowledge and highly appreciate the support and encouragement provided by Mr. Mansour Al Askar-Executive Director Prince Muhammad Bin Abdulaziz Hospital, Madinah Al Munawarah-MNGHA. We also acknowledge our Clinical Dietitians at Prince Muhammad Bin Abdulaziz Hospital- Madinah Al Munawarah, Ms. Bushra Alharthi, Ms.Nur Adila and Ms. Marwa Al Qarras and all those interns from Taiba University who played a role in the collection of data along with the author and co-authors of this study. We also acknowledge the help extended by Nursing staff namely Mr. Ehab, Kuhail Khldon Hassan, Eyad Numan, Haitham sarhan in data collection. Special thanks for Ms. Eshraq Al oufi for all her secretarial support during proposal writing and data entry and amalgamation. Bundle of thanks go to the Ministry of Education and their dedicated staff, school administration, teachers, students and their parents in Madinah region for their full cooperation. Last but not least King Abdullah International Medical research Centre for their supervision extensive guidance, technical support provided by Institutional Review Board (IRB) and research funding Committee (RFC) for financial support to conduct the study as per GCP /ICH standards.

\section{References}

1. The global syndemic of obesity, undernutrition, and climate change. The Lancet Commission (2017).

2. World Obesity Foundation (2019).

3. NCD Risk Factor Collaboration (NCD-RisC) Trends in adult body-mass index in 200 countries from 1975 to 2014: A pooled analysis of 1698 population-based measurement studies with $19 \cdot 2$ million participants. Lancet (2016) 387: 1377-1396.

4. Roberto CA, Swinburn B, Hawkes C, Cawley JH, Ashe M, et al. Patchy progress on obesity prevention: emerging examples, entrenched barriers, and new thinking. Lancet (2015) 385: 2400-2409.

5. Abarca-Gómez, L, Abdeen, ZA, Hamid, ZA, Abdeen ZA, Adaams RJ, et al. Worldwide trends in body-mass index, underweight, overweight, and obesity from 1975 to 2016: a pooled analysis of 2416 population-based measurement studies in 128.9 million children, adolescents, and adults. Lancet (2017) 390(10113): 2627-2642.

6. UNICEF, WHO, World Bank. Levels and trends in child malnutrition: UNICEF-WHO-World Bank joint child malnutrition estimates. UNICEF, New York; WHO, Geneva; World Bank, Washington DC: (2015).

7. World Health Organization. Global status report on non-communicable diseases. Geneva, Switzerland (2014).

8. Al Nuaim AR, Bamgboye EA, Al Herbish A. The pattern of growth and obesity in Saudi Arabian male school children. Int J Obes Relat Metab Disord (1996) 20: 1000-1005. 
9. Al Almaie SM Prevalence of obesity and overweight among Saudi adolescents in Eastern Saudi Arabia. Saudi Med J (2005) 26: 607-611.

10. Al Hazzaa HM Prevalence and trend in obesity among schoolchildren in Central Saudi Arabia between 1988 and 2005. Saudi Med J (2007); 28: 1569-1574.

11. Mohammad I, Mouzan, Foster PJ, Herbish AS, Ahmad A, et al. Prevalence of overweight and obesity in Saudi children and adolescents. Ann Saudi Med (2010); 30(3): 203-208.

12. Stunkard AJ, Harris JR, Pedersen NL, McClearn GE The body-mass index of twins who have been reared apart. N Engl J Med (1990); 322(21): 1483-1487.

13. Stunkard AJ, Sørensen TI, Hanis C, Teasdale TW, Chakraborty R, et al. An adoption study of human obesity. N Engl J Med (1986); 314(4): 193-198.

14. Rodenhiser D, Mann M. Epigenetics and human disease: Translating basic biology into clinical applications. CMAJ (2006); 174(3): 341-8.

15. Gluckman PD, Hanson MA. Developmental and epigenetic pathways to obesity: An evolutionary-developmental perspective. International Journal of Obesity (2008) ; (32): S62-S71.

16. Mutch DM, Clement K Unraveling the genetics of human obesity. PLoS Genet (2006); 2(12): e188.

17. Plagemann A, Harder T, Brunn M, Kerstin M, Anja H, et al. Hypothalamic proopiomelanocortin promoter methylation becomes altered by early overfeeding: An epigenetic model of obesity and the metabolic syndrome. Journal of Physiology (2009); 587: 4963-4976.

18. Seki Y, Williams L, Vuguin PM, Charron MJ. Minireview: Epigenetic programming of diabetes and obesity: animal models. Endocrinology (2012); 153: 1031-38.

19. Slomko H, Heo HJ, Einstein FH. Minireview: Epigenetics of obesity and diabetes in humans. Endocrinology (2012); 153: 1025-1030.

20. Godfrey KM, Sheppard A, Gluckman PD, Cooper C, Hanson MA, et al. Epigenetic gene promoter methylation at birth is associated with child's later adiposity. Diabetes (2011); 60: 1528-1534.

21. Ravelli GP, Stein ZA, Susser MW. Obesity in young men after famine exposure in utero and early infancy. New England Journal of Medicine (1976); 295: 349-353.

22. Lake A, Townshend T, Obesogenic environments: Exploring the built and food environments. J R Soc Promot Health (2006); 126: 262-267.

23. Lobstein T, Jackson Leach R Estimated burden of paediatric obesity and co-morbidities in Europe. Part 2. Numbers of children with indicators

\section{ISSN: 2574-1241}

DOI: 10.26717/BJSTR.2019.21.003538

Atta ur Rehman Khan. Biomed J Sci \& Tech Res

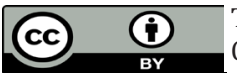

This work is licensed under Creative

Commons Attribution 4.0 License

Submission Link: https://biomedres.us/submit-manuscript.php of obesity-related disease. International Journal of Pediatric Obesity (2006); 1: 33-41.

24. Pizzi MA, Vroman K Childhood obesity: effects on children's participation, mental health, and psychosocial development. Occup Ther Health Care (2013); 27: 99-112.

25. Pediatr ResMiller AL, Lee HJ, Lumeng JC Obesity-associated biomarkers and executive function in children. Pediatr Res (2015); 77: 143-147.

26. litwin se. childhood obesity and adulthood cardiovascular disease: quantifying the lifetime cumulative burden of cardiovascular risk factors. J Am Coll Cardiol (2014); 64: 1588-1590.

27. Nader PR, O’Brien M, Houts R, Bradley R, Belsky J, Crosnoe R, et al. Identifying risk for obesity in early childhood. Pediatrics (2006); 118: e594-e601.

28. Juonala M, Magnussen CG, Berenson GS Childhood adiposity, adult adiposity, and cardiovascular risk factors. N Engl J Med (2011); 365: 1876-1885.

29. Barlow SE. Expert Committee. Recommendations regarding the prevention, assessment, and treatment of child and adolescent overweight and obesity: Summary report. Pediatrics (2007); 120: S164-S192.

30. Centers for Disease Control and Prevention, National Center for Health Statistics (2000).

31. Caballero B. The global epidemic of obesity: An overview. Epidemiol Rev (2007); 29: 1-5.

32. WHO Prevalence of overweight and obesity in children and adolescents FACT SHEET (2018).

33. Kopelman P Health. Health risks associated with overweight and obesity. Obes Rev (2007); 8(S1): 13-17.

34. Adair LS. Child and adolescent obesity: Epidemiology and developmental perspectives. Physiol Behav (2008); 94: 8-16.

35. WHO Prevalence of overweight and obesity in children and adolescents FACT SHEET (2019).

36. Al-Hazzaa HM, Abahussain N, Al-Sobayel H, Qahwaji D, Musaiger AO. Physical Activity, Sedentary Behaviors and Dietary Habits among Saudi Adolescents Relative to Age, Gender and Region. Int J Behav Nutr Phys Act (2011); 2(8): 140 .

37. AlHazzaa HM, Abahussain NA, AlSobayel HI, Qahwaji DM, Alsulaiman NA, et al. Prevalence of overweight, obesity, and abdominal obesity among urban Saudi adolescents: gender and regional variations. J Health Popul Nutr (2014); 32(4): 634-645

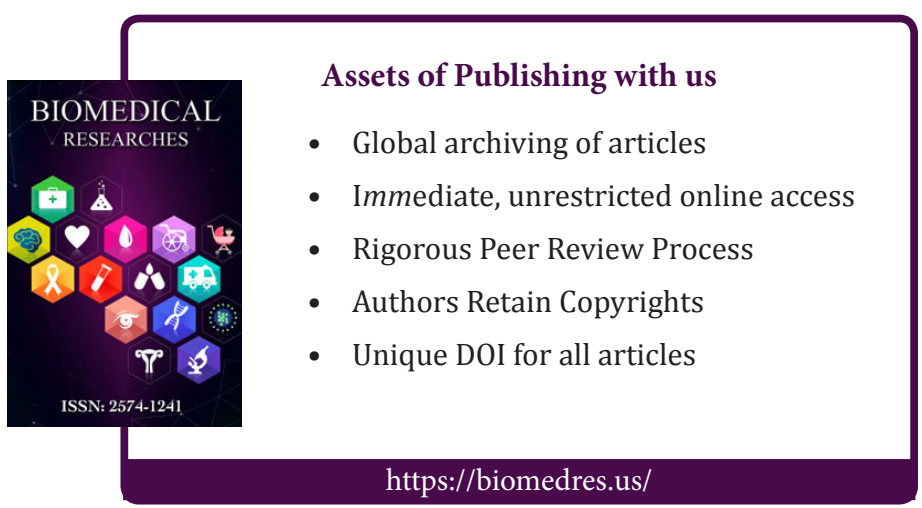

